\title{
A 5-year longitudinal study of schistosomiasis transmission in Shian village, the Anning River Valley, Sichuan Province, the Peoples' Republic of China
}

Rong Zhu ${ }^{1,2+}$, Darren J Gray ${ }^{3,4+}{ }^{4}$ Aaron P Thrift ${ }^{4,5}$, Gail M Williams ${ }^{5}, Y_{i}$ Zhang $^{6}$, Dong-Chuan Qiu ${ }^{6}$, Feng Zheng ${ }^{1}$, Yue-Sheng $\mathrm{Li}^{4,7}$, Jiagang Guo ${ }^{1 *}$, Hong-Qing Zhu' ${ }^{1}$, Wei-Ping $\mathrm{Wu}^{1}$, Robert $\mathrm{S} \mathrm{Li}^{5}$ and Donald P McManus ${ }^{4}$

\begin{abstract}
Background: Schistosoma japonicum is a major public health concern in the Peoples' Republic of China (PRC), with over one million people infected and another 50 million living in areas at risk of infection. Based on ecological, environmental, population genetic and molecular factors, schistosomiasis transmission in PRC can be categorised into four discrete ecosystems or transmission modes. It is predicted that the Three Gorges Dam (TGD) will impact upon the transmission of schistosomiasis in the PRC, with varying degree across the four transmission modes. We undertook longitudinal surveillance from 2002 to 2006 in sentinel villages both above and below the TGD across five provinces (Hunan, Jiangxi, Hubei, Anhui and Sichuan) to determine whether there was any impact of the TGD on schistosomiasis transmission during its construction. Here we present the results from a schistosomiasis-endemic village located above the dam in Sichuan Province.

Results: Baseline results showed a human S. japonicum prevalence of $42.0 \%$ (95\% Cl: 36.6-47.5). At follow-up, results showed that the incidence of $S$. japonicum infection in the selected human cohort in Shian decreased by three quarters from 46\% in 2003 to 11.3\% in 2006. A significant $(P<0.01)$ downward trend was also evident in the yearly adjusted (for water contact) odds ratios. Over the four years of follow-up, the incidence of S. japonicum infection in bovines declined from $11.8 \%$ in the first year to zero in the final year of follow-up.

Conclusions: The substantial decrease in human (75\%) and bovine (100\%) incidence observed in Shian village can probably be attributed to the annual human and bovine PZQ treatment of positives; as seen in drug (PZQ) intervention studies in other parts of PRC. If an increase in schistosome transmission had occurred as a result of the TGD, it would be of negligible size compared to the treatment induced decline seen here. It appears therefore that the construction of the TGD had virtually no impact on schistosomiasis transmission in Shian village over the period of study. Furthermore, contrary to previous reports from Sichuan downplaying the role of animals in human schistosome transmission, bovines may indeed play a role.
\end{abstract}

\section{Introduction}

In the People's Republic of China (PRC), zoonotic schistosomiasis, caused by Schistosoma japonicum, is a chronic debilitating disease with 50 million people at risk of infection [1]. Endemic foci are located in the lake and marshland regions of Southern China (Jiangxi, Hunan,

\footnotetext{
* Correspondence: jiagangg@gmail.com

+ Contributed equally

'National Institute of Parasitic Disease, Chinese Centre for Disease Control and Prevention, Shanghai, PR China

Full list of author information is available at the end of the article
}

Jiangsu, Anhui and Hubei provinces), where the majority of transmission occurs, and in the hilly and mountainous regions of Sichuan and Yunnan [1]. Based on ecological, environmental, population genetic and molecular factors, Davis et al. [2] categorised schistosomiasis transmission in the PRC into four discrete ecosystems or transmission modes. These are represented by Poyang Lake (mode I), Dongting Lake (mode II), the Yangtze River isles of Anhui (mode II), the canals and water networks of Hubei (mode III), and the hilly and mountainous areas of Sichuan and Yunnan (mode IV) [2].

\section{C) Biomed Central}


It is predicted that the Three Gorges Dam (TGD) will impact upon the transmission of schistosomiasis in the PRC, with varying degree across the four transmission modes [3,4]. Transmission Modes I-III are located below the dam and mode IV is above the dam. The dam is located in the Three Gorges region in the upper reaches of the Yangtze River (the world's third-largest river; $5920 \mathrm{~km}$ long) (Figure 1). It spans the Yangtze at Sandouping Island, just west of the city of Yichang in Hubei province $[1,3,4]$. It is the world's largest hydroelectric project aimed at developing and controlling the Yangtze River, reducing flooding in the lower plains regions, and hence ameliorating economic losses $[1,3,4]$. Construction commenced in 1994 and by 2003 the TGD was closed to a height of 135 metres. In 2009, it reached its full height of 185 metres and began to generate 18,600MW of power for the whole of the PRC [5]. The dam will also help to control the lower Yangtze which is prone to periodic flooding. By 2009, the 2,300 $\mathrm{m}$ long dam resulted in a $600 \mathrm{~km}$ long reservoir that inundated 115,000 acres of cultivated land, requiring resettlement of some two million people [5].
We undertook longitudinal surveillance from 2002 to 2006 in sentinel villages both above and below the TGD across five provinces (Hunan, Jiangxi, Hubei, Anhui and Sichuan) to determine whether there was any impact of the TGD on schistosomiasis transmission during its construction. Here we present the results from a schistosomiasis-endemic village located above the dam in Sichuan Province.

\section{Methods}

\section{Study design}

We undertook a prospective longitudinal cohort study in the residents of Shian village, located at $27.84284 \mathrm{~N}$, 102.39277E, in the Anning River Valley, Sichuan Province, PRC (Figure 1) between 2002 and 2006, to determine the impact, if any, of the construction of the TGD on schistosome transmission. The primary end point measured was human incidence.

\section{Baseline}

At baseline, two stool samples were collected and a questionnaire administered to all residents $(\mathrm{N}=319)$ who

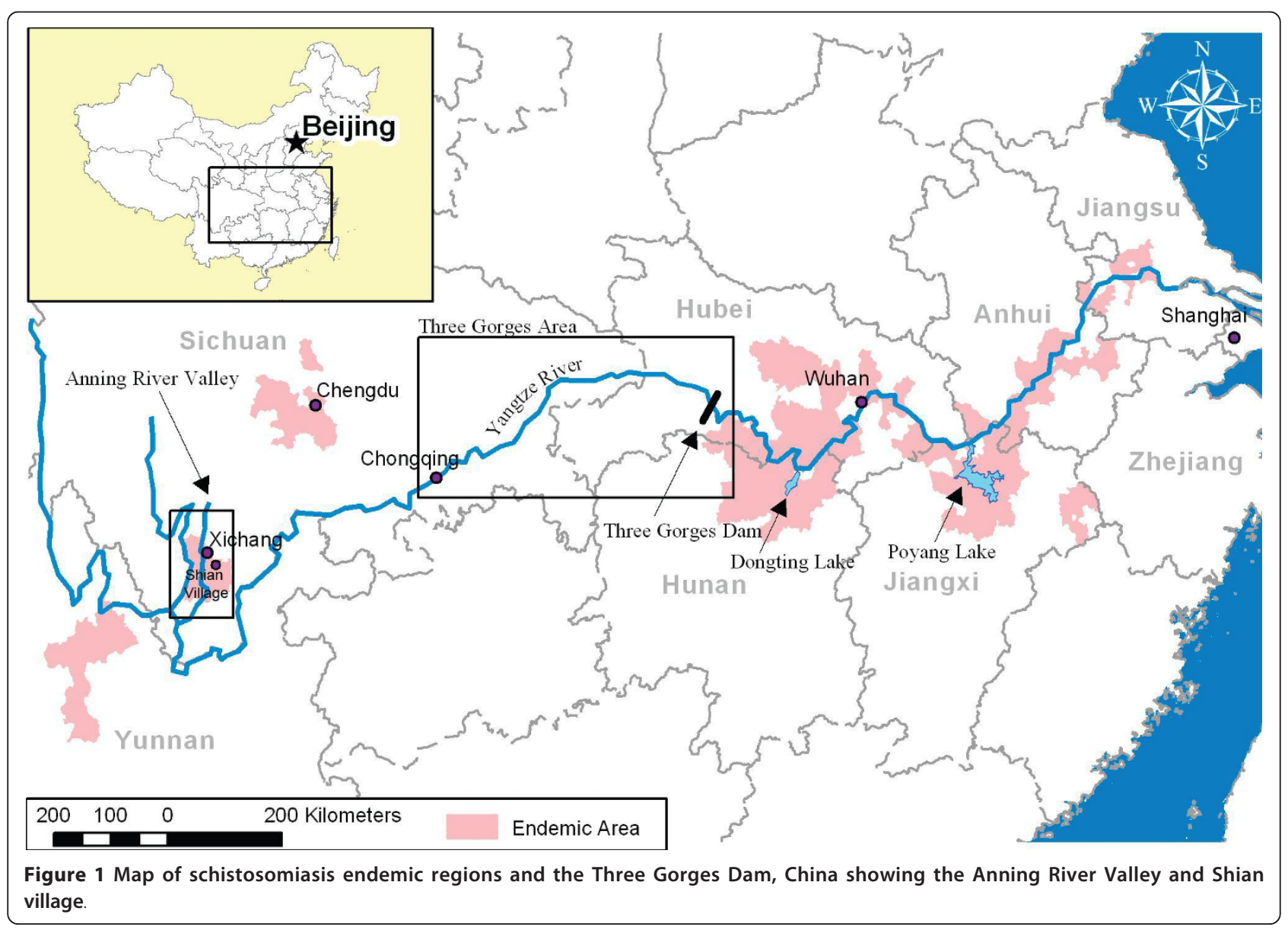


usually resided in the village. Stool samples were examined microscopically using the Kato-Katz thick smear technique, with three slides per stool read blind, to determine $S$. japonicum prevalence and intensity of infection [6]. The questionnaire consisted of questions relating to demographics, medical history and water contact.

A stool sample was also collected from all bovines in Shian village and examined for S. japonicum prevalence using the miracidial hatching test (3 individual hatches read blind - 50 grams faeces/hatching) and intensity of infection, using a traditional Chinese sedimentation method [7].

\section{Follow-up and study procedures}

Following the baseline survey, a fixed cohort of villagers $(\mathrm{N}=285)$ was selected and monitored for schistosome infections for the duration of the study. The cohort inclusion criteria were that an individual must be: a) a resident of the village for more than 12 months; b) aged 5-65 years; d) not intending to migrate out of the village for the next 4 years; e) continuously reside in the study area over the study period. With a final cohort size of 240 residents and a 95\% confidence interval for infection rates we will have a half-width of $3.15 \%$.

A water contact questionnaire was administered to the cohort members annually; and consisted of general questions relating to participant yearly water exposure by season; as well, a month-long water contact diary was kept by each individual [8].

Two stool samples were collected from all cohort members and one stool sample from all bovines to determine outcome measures, which included incidence and intensity of infection for cohort members, and infection rates and intensity of infection for bovines.

\section{Treatment regime}

At baseline all village residents and bovines found positive were treated with praziquantel (PZQ) (humans: $40 \mathrm{mg} / \mathrm{kg}$; bovines: $25 \mathrm{mg} / \mathrm{kg}$ ) as recommended by WHO [9] until cleared of infection. Previous studies in Poyang and Dongting Lakes showed 85-95\% efficacy for a single PZQ dose in humans $(40 \mathrm{mg} / \mathrm{kg})$ and water buffaloes $(25$ $\mathrm{mg} / \mathrm{kg}$ ), with $100 \%$ efficacy following re-examination and re-treatment [10-12]. At follow-up all cohort members and all bovines found positive were treated with PZQ (humans: $40 \mathrm{mg} / \mathrm{kg}$; bovines: $25 \mathrm{mg} / \mathrm{kg}$ )) as recommended by WHO until cleared of infection [9].

\section{Snail surveys}

A snail survey was performed in April each year to measure the prevalence of infection in snails and the density of infected snails per unit area. This was conducted using the Chinese method of random quadrat sampling
(0.11 metres ${ }^{2}$ sized frames, 20 metres between frames) of the marshland areas.

\section{Rainfall readings}

Rainfall readings were taken every 10 days from two nearby weather stations. These were collected for the duration of the follow-up period (2003-2006).

\section{Data management and statistical analyses}

An MS ACCESS based database was designed specifically for this project and was used for data management [13]. Presence of human infection was defined as at least one egg in all Kato-Katz smears. Egg counts were transformed to eggs per gram and geometric mean intensity was calculated by using the log-transformed egg counts. Confidence intervals (CIs) were calculated using standard formulae based on the binomial distribution (annual incidence of infection) and the lognormal distribution (intensity). Each cohort member was assigned a water contact score for each year preceding infection status assessment. This was determined by adding season-specific subscores based on frequency of water contact obtained through the water contact diaries. Formal analyses of annual human incidences, both crude and adjusted (for water contact, using the water contact score), used a generalized linear model (GLM) with a logit link and a binomial error distribution. Generalised equation estimators of parameters with an unstructured variance-covariance matrix were used to account for repeated measures on individuals over time. Analyses used the GENMOD procedure of SAS software (version 9.1; SAS Institute, Inc, Cary, NC) to calculate odds ratios (OR) and 95\% confidence intervals (95\% CIs).

\section{Ethical considerations}

Written ethical approval for this study was obtained at the national, Sichuan provincial and Shian village, levels; the Human Research Ethics Committee of the Queensland Institute of Medical Research also granted approval for the study. Written informed consent was obtained from all adults and from parents or guardians of minors who were involved in the project. Study participants and bovines identified as positive for schistosomiasis were treated with $40 \mathrm{mg} / \mathrm{kg}$ PZQ (25 mg/kg PZQ for bovines) [9].

\section{Results \\ Baseline \\ Human prevalence and intensity of infection}

Baseline human prevalence (\%) and intensity of infection (geometric mean eggs per gram (GMEPG) in the infected individuals) for S. japonicum within Shian village was $42.0 \%(95 \% \mathrm{CI}: 36.6-47.5)(\mathrm{N}=319)$ and 32.8 GMEPG (95\% CI: 26.9-40.1), respectively (Table 1). 
Table 1 S. japonicum prevalence and intensity of infection in the human cohort from Shian village, Anning River Valley, Sichuan Province, People's Republic of China at baseline in 2002

\begin{tabular}{ccccc}
\hline Human Cohort & Sub-group & $\mathbf{N}$ & $\begin{array}{c}\text { Prevalence } \\
\mathbf{( 9 5 \%} \mathbf{C I})\end{array}$ & $\begin{array}{c}\text { Intensity EPG } \\
\mathbf{( 9 5 \%} \mathbf{C I})\end{array}$ \\
\hline All & & 319 & $42.0 \%(36.6,47.5)$ & $32.8(26.9,40.1)$ \\
\hline Sex & Female & 162 & $41.4 \%(33.7,49.0)$ & $34.4(25.8,45.8)$ \\
& Male & 157 & $42.7 \%(34.9,50.5)$ & $31.4(23.6,41.7)$ \\
\hline Age & $5-10$ & 56 & $23.2 \%(11.8,34.6)$ & $19.2(9.1,40.3)$ \\
& $11-20$ & 42 & $23.8 \%(10.4,37.2)$ & $32.7(13.2,81.0)$ \\
& $21-30$ & 44 & $43.2 \%(27.9,58.4)$ & $35.4(21.3,59.0)$ \\
& $31-40$ & 79 & $51.9 \%(40.6,63.2)$ & $38.0(25.2,57.4)$ \\
& $41-50$ & 45 & $57.8 \%(42.8,72.8)$ & $28.7(19.7,41.8)$ \\
& $51-60$ & 33 & $48.5 \%(30.5,66.5)$ & $40.0(22.1,72.2)$ \\
\hline Occupation & $61-65$ & 19 & $42.1 \%(17.7,66.6)$ & $30.9(9.3,102.7)$ \\
\hline & Farmer & 241 & $47.3 \%(41.0,53.7)$ & $35.1(28.4,43.3)$ \\
& Pre-school & 18 & $22.2 \%(0.9,43.5)$ & $16.2(2.0,133.5)$ \\
\hline
\end{tabular}

\section{Human prevalence by sex, age and occupation}

There were more females $(\mathrm{N}=162)$ than males $(\mathrm{N}=$ $157)$ in the selected cohort at baseline. Infection prevalence was higher in males (42.7\%; 95\% CI: 34.9-50.5) than females (41.4\%; 95\% CI: 33.7-49.0) (Table 1).

The average age of people in the cohort was 32 years. Prevalence within the age groups is shown in Table 1. All age groups had prevalences above $20 \%$, with those between 41-50 years of age having the highest (57.8\%; 95\% CI: 42.8-72.8).

The majority of the cohort were farmers or fishermen $(\mathrm{N}=241)$, followed by students $(\mathrm{N}=59)$ and pre-school children $(\mathrm{N}=18)$ (Table 1$)$. The highest prevalence was found in the farmer or fisherman group (47.3\%; 95\% CI: 41.0-53.7) and the lowest was in the pre-school children group (22.2\%; 95\% CI: 0.9-43.5).

Bovine prevalence and intensity of infection

Baseline bovine prevalence (\%) for S. japonicum was 29.4\% (95\% CI: 5.3-53.6) $(\mathrm{N}=17)$ and the intensity of infection was low (<1 GMEPG) (Table 2).

Table 2 S. japonicum infection rates $(95 \% \mathrm{CI})$ in bovines at baseline and at follow up

\begin{tabular}{ccc}
\hline Year & $\mathbf{N}$ & $\begin{array}{c}\text { Infection Rates } \\
(\mathbf{9 5 \%} \mathrm{Cl})\end{array}$ \\
\hline $\mathbf{2 0 0 2}$ & 17 & $29.4 \%$ \\
& & $(5.3,53.6)$ \\
$\mathbf{2 0 0 3}$ & 17 & $11.8 \%$ \\
& & $(0.0,28.9)$ \\
$\mathbf{2 0 0 4}$ & 17 & $17.6 \%$ \\
& & $(0.0,37.9)$ \\
2005 & 16 & $6.3 \%$ \\
& & $(0.0,19.6)$ \\
& 15 & $0.0 \%$ \\
& & $(\mathrm{~N} / \mathrm{A})$ \\
\hline
\end{tabular}

\section{Follow-up}

Participant flow

Within Shian village, a cohort of people was selected for follow-up over the course of the study. The flow of these study participants is shown in Table 3 . Loss to follow-up per year was small ranging from $0.4 \%$ to $10.7 \%$; and the attrition rate for the entire study was $24.8 \%$ which is low given the duration of follow-up (4 years). Human treatment coverage was high with $98-100 \%$ of those found infected treated with $\mathrm{PZQ}$.

\section{Human incidence and intensity of infection}

Over the four years of follow-up, the incidence of S. japonicum infection declined from $46.0 \%$ (95\% CI: $40.1-51.8)$ in the first year of follow-up to $11.3 \%$ (95\% CI: 7.2-15.3) in the final year (Table 3). Intensity of infection also decreased from 23.5 GMEPG (95\% CI: 18.4-30.0) in the first year of follow-up to 12.3 GMEPG (95\% CI: 8.0-18.9) in the final year (Table 3).

Regression analyses yielding crude and adjusted (for water contact) odds ratios (OR) (Figure 2) for each year of the study were the same. A significant $(\mathrm{P}<0.01)$ downward trend was observed and was in concordance with S. japonicum incidence.

Table 3 S. japonicum incidence and intensity of infection in the human cohort at follow up

\begin{tabular}{cccc}
\hline Follow-up & $\mathbf{N}$ & $\begin{array}{c}\text { Incidence } \\
(\mathbf{9 5 \%} \mathrm{Cl})\end{array}$ & $\begin{array}{c}\text { Intensity EPG } \\
\mathbf{( 9 5 \% ~ C l )}\end{array}$ \\
\hline $\mathbf{2 0 0 3}$ & 285 & $46.0 \%$ & 23.5 \\
& & $(40.1,51.8)$ & $(18.4,30.0)$ \\
$\mathbf{2 0 0 4}$ & 257 & $31.5 \%$ & 20.9 \\
& & $(25.8,37.2)$ & $(15.4,28.4)$ \\
$\mathbf{2 0 0 5}$ & 256 & $20.3 \%$ & 14.2 \\
& & $(15.4,25.3)$ & $(10.3,19.7)$ \\
$\mathbf{2 0 0 6}$ & 240 & $11.3 \%$ & 12.3 \\
& & $(7.2,15.3)$ & $(8.0,18.9)$ \\
\hline
\end{tabular}




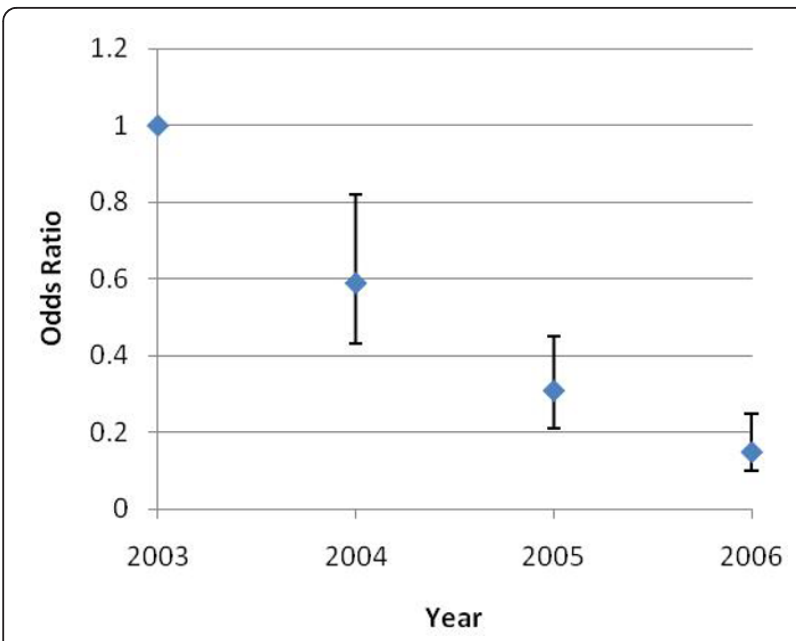

Figure 2 Annual Schistosoma japonicum infection risk in subjects from Shian village (Odds Ratios - adjusted for water contact - with $95 \% \mathrm{Cl}$ )

Human incidence by sex, age and occupation

Over the course of the study, the ratio of cohort males to females remained steady and similar to baseline, although in the final year there were slightly more males $(\mathrm{N}=123)$ than females $(\mathrm{N}=117)$. The $S$. japonicum incidence decreased in females and, especially in males (Figure 3).

In general the incidence decreased from the first to the final year of follow-up in all age groups, although reductions within groups were inconsistent (Figure 4). Similar decreasing trends were evident for occupation during the four years of follow-up, although the incidence plateaued in students in the final year (Figure 5).

\section{New human infections and re-infection rates}

New infection (those not infected in the previous year) and re-infection (those infected in the previous year) rates were calculated over the duration of the study. In 2003 there was a $40.0 \%$ infection rate of new infections, this fell to $8.3 \%$ in 2006 (Table 4). Re-infection was

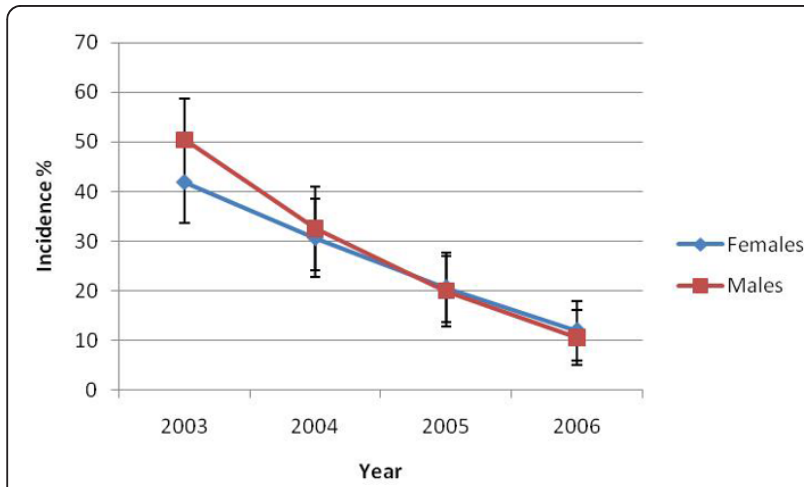

Figure 3 Human S. japonicum incidence over time in males and females (with $95 \% \mathrm{Cl}$ ).

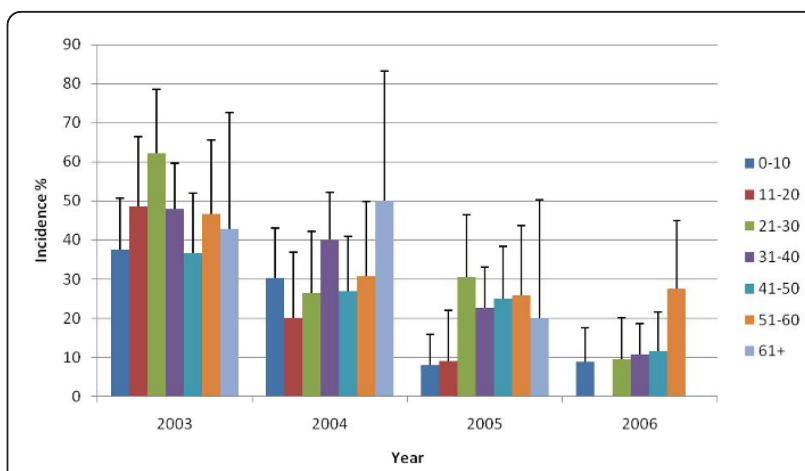

Figure 4 Human S. japonicum incidence over time by age (with $95 \% \mathrm{Cl}$ ).

greater than new infections over the course of the study although they did follow the same declining trend (53.4\% in 2003 to $23.4 \%$ in 2006 (Table 4)) as new infections. Both followed the same trend as the overall incidence (Table 3).

\section{Bovine infection rates and intensity of infection}

Over the four years of follow-up, S. japonicum infection rates declined from $11.8 \%$ (95\% CI: -5.3-28.8) in the first year to zero in the final year of follow-up. In 2004 there was a slight increase in prevalence from $11.8 \%$ (2003) to 17.6\% (95\% CI: -2.6-37.8) (Table 2). The intensity of infection remained low (<1 GMEPG).

\section{Dynamics of infected snails}

The prevalence and density of infected snails fluctuated substantially over the duration of the study period and consistent trends could not be identified. This was probably because of high levels of snail sampling variability due to spatial aggregation effects that we have observed previously [14].

\section{Rainfall patterns}

Rainfall patterns were similar over the duration of the study with peak rainfall in the summer (Figure 6). There

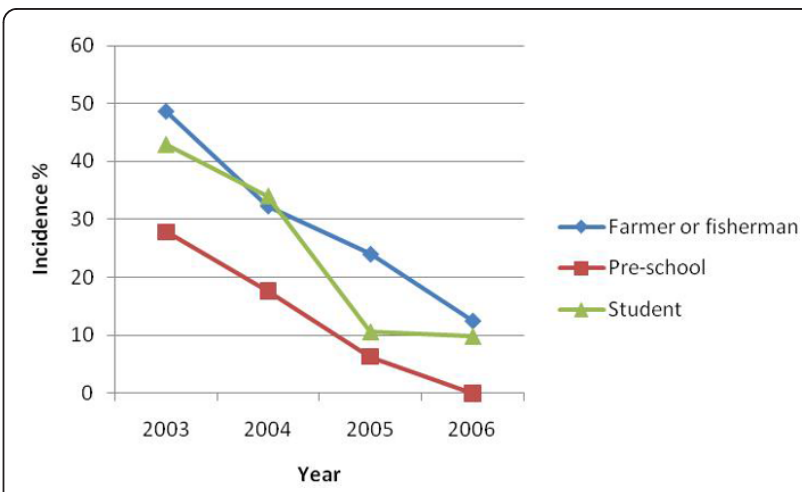

Figure 5 Human $S$. japonicum incidence over time by occupation. 
Table 4 New human S. japonicum infection rates and reinfection rates over time

\begin{tabular}{cccc}
\hline Follow-up & $\begin{array}{c}\text { New Infection Rates } \\
(\mathbf{9 5 \%} \mathbf{~ C l})\end{array}$ & $\begin{array}{c}\text { Re-infection Rates } \\
(\mathbf{9 5 \%} \mathbf{C l})\end{array}$ & P-value \\
\hline $\mathbf{2 0 0 3}$ & $40.0 \%$ & $53.4 \%$ & $<0.05$ \\
& $(32.4,47.6)$ & $(44.2,62.7)$ & \\
$\mathbf{2 0 0 4}$ & $16.2 \%$ & 45.5 & $<0.001$ \\
& $(10.1,22.3)$ & $(34.1,56.8)$ & \\
$\mathbf{2 0 0 5}$ & $16.1 \%$ & 29.6 & $<0.05$ \\
& $(10.6,22.3)$ & $(19.5,39.8)$ & \\
$\mathbf{2 0 0 6}$ & $8.3 \%$ & 23.4 & $<0.01$ \\
& $(4.4,12.2)$ & $(10.8,36.0)$ & \\
\hline
\end{tabular}

was more rainfall in 2004 and 2006 but there were no reports of major flooding in these two years.

\section{Discussion and Conclusion}

Schistosomiasis transmission in Sichuan (Mode IV) is thought to be quite different to the other transmission modes in the PRC, particularly Modes I - II (Dongting and Poyang lakes) below the TGD [1,2]. Transmission in Sichuan is quite focal and, in the Anning river valley area, the snail habitats lie along the edges of vegetation irrigation ditches, compared with their distribution on the lake shores, on the vast marshlands or along the banks of rivers, canals and water networks in the schistosome-endemic areas below the TGD $[15,16]$. Oncomelania hupensis robertsoni, which harbours S. japonicum in Sichuan evolved only at high elevations above the Three Gorges in Sichuan and Yunnan Provinces and is a distinct subspecies to that (Oncomelania hupensis hupensis) present below the dam [15]. Furthermore, mixed agriculture is practiced in Sichuan and this does not rely on animal husbandry to the extent operating in the lake and marshland areas. Consequently, bovines, which play a major role in $S$. japonicum transmission below the TGD, may only have a minor role in Sichuan where transmission is thought to be perpetuated through the use of schistosome-egg laden faeces as fertiliser ("night soil") [15-20].

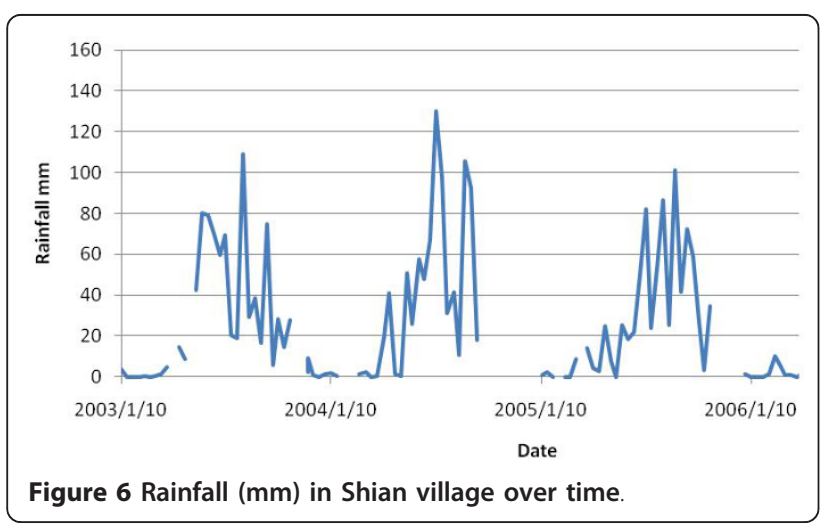

It is predicted that the TGD will change water and sand distributions downstream, hence having a significant impact on ecological systems including the Dongting and Poyang lakes and the canals of Hubei, where S. japonicum transmission is generally projected to increase; although it may in fact decrease in some foci $[1,3,21]$. This is in accordance with other large-scale hydroprojects such as the Gezira-Managil Dam in Sudan, the Aswan Dam in Egypt, the Melkasadi Dam in Ethiopia, and the Danling and Huangshi Dams in China, where schistosomiasis emergences or re-emergences have resulted [22].

The Three Gorges region above the dam is not currently endemic for schistosomiasis due to the previous rapidly flowing waterway that was extremely hostile for snail reproduction and, to date, no oncomelanid snails have been detected there $[1,4]$. However, the $600 \mathrm{~km}$ lake created behind the dam that stretches up-stream now has shorelines suitable in many areas for snail breeding and schistosome transmission. The lake is located between two key transmission zones of S. japonicum - Sichuan and Hubei-Hunan. The downstream schistosomiasis-free buffer is only $40 \mathrm{~km}$ and the upstream buffer is $500 \mathrm{~km}$. It is anticipated that, in time, these two endemic areas will merge into one, thus potentially spreading the disease into a new location $[1,4]$. It is projected that the spread of schistosomiasis into this currently non-endemic area would be expedited by infected humans travelling on the newly created waterways and by the introduction of oncomelanid snails $[1,4]$. Once schistosomes are established in the lake they would be difficult to eliminate [23].

We hypothesised that the TGD would have little or no impact on transmission in areas currently endemic for S. japonicum in Sichuan Province; and that the creation of new endemic areas would take upward of 10 years as the water flow slows down and silt deposits settle, forming new marshland areas. Snail dispersal and population movements will also be required to introduce schistosomes into these areas.

We undertook longitudinal surveillance from 2002 to 2006 in Shian village in the Anning river valley of Sichuan Province, to determine the immediate impact upstream of the construction of the TGD on schistosome transmission. The results showed that the incidence of $S$. japonicum infection in the selected human cohort decreased by three quarters from $46 \%$ in 2003 to $11.3 \%$ in 2006 (Table 3$)$. A significant $(\mathrm{P}<0.01)$ downward trend was also evident in the yearly adjusted (for water contact) odds ratios (Figure 2).

The decrease in human incidence observed in Shian village may be attributed to the annual PZQ treatment administered to infected individuals (ethical reasons). Torrential rains that sometimes occur in regions of high 
terrain inclination (Sichuan) can wash snails down to lowland sites thus decreasing transmission [20], but this had not occurred in Shian (Figure 6). However, the concurrent decline in bovine infection rates observed in Shian suggests that this may also have contributed to the decline in human incidence. Studies have shown that bovines are the major transmission source of human schistosomiasis in the Dongting and Poyang lakes and marshland areas and that interventions targeting bovines reduce the incidence of human infection $[17,18]$. This study of Shian village suggests that bovines may also be important for human transmission in Sichuan, which is contrary to previous reports that downplay the role of animals, particularly bovines, in schistosome transmission in Sichuan $[15,16]$. It is noteworthy as well that a recent article by Zou et al, shows that domestic livestock, particularly bovines, are important in schistosomiasis transmission in Yunnan Province [24]. The bovine involvement in transmission may be through either direct contamination of the environment or through the use of their schistosome-egg laden faeces for crop fertilisation. Nevertheless, they should be targeted by control programs in this region.

The substantial decrease in human (75\%) and bovine $(100 \%)$ incidence observed in Shian village can probably be attributed to the annual human and bovine PZQ treatment of positives; as seen in drug (PZQ) intervention studies in other parts of PRC [18]. It should be noted no decrease in exposure was seen as that water contact patterns did not change over the duration of the study, indicated by the similarity in crude and adjusted (for water contact) OR. If an increase in schistosome transmission had occurred as a result of the TGD, it would be of negligible size compared to the treatment induced decline seen here. It appears therefore that the construction of the TGD had virtually no impact on schistosomiasis transmission in Shian village over the period of study.

Another finding of note is that despite the trend of decline, in accordance with overall incidence, re-infection rates were higher than new infection rates over the duration of the study (Table 4), thus suggesting that many of the same people were becoming infected in this village. This gives insight for future control, as interventions, particularly chemotherapy and health education, can be directed towards this group of people.

A recent article by Liang et al [25] demonstrated that schistosomiasis is re-emerging in Sichuan Province, particularly in previously endemic areas, classified recently by the Chinese authorities as under transmission control (S. japonicum prevalence in humans and bovines is $<1 \%$ ) or transmission interruption (S. japonicum prevalence in humans and bovines is $<0.2 \%)$. It is likely that this re-emergence, signalled by the occurrence of acute infections, is due to changes in the socio-political and economic (diminished funding and awareness for schistosomiasis control) climates and in the local environment and surveillance systems and increased human mobility from non-endemic areas and inappropriate surveillance [25]. These changes have major implications for future control efforts especially with the future threat of the development of new schistosome-endemic areas due to construction and completion of the TGD $[1,3,4]$.

PZQ treatment alone will not be able to mitigate schistosome re-emergence, prevent increases in transmission or avert the creation of new endemic areas. This is due to the inability of the drug to prevent re-infection [26]. This is exemplified by the current study where, even after 5 years of annual PZQ treatment, despite a decrease in human incidence, it was still over $10 \%$ (Table 3 ). As mathematical modelling has shown, incidence will rebound to pre-treatment levels on its cessation [27]. Therefore, a multi-component, integrated control program $[1,26]$ will be required to combat the spread of schistosomiasis and achieve the Chinese Government's goal of reducing the prevalence of S. japonicum to less than $1 \%$ by 2014 [28]. Indeed, pilot programs are already in place in the PRC where new integrated strategies have been instigated to prevent schistosome eggs contaminating the environment. These emphasise health education, access to clean water and adequate sanitation, mechanisation of agriculture, fencing of water buffaloes, snail control, chemotherapy, and even future vaccination of livestock [28-30].

\section{Acknowledgements \& funding}

We would like to thank all staff at the Sichuan Provincial Institute for Parasitic Diseases CDC, and the villagers who participated in the study. This Project was funded by the National Institutes of Health (NIH-USA) under the Tropical Medicine Research Centre (TMRC) scheme; The Wellcome Trust (WT) and the National Health and Medical Research Council (NHMRC), Australia. Donald P McManus is a NHMRC Senior Principal Research Fellow; Yuesheng $\mathrm{Li}$ is an Australian Research Council Future Fellow and a Howard Hughes Medical Institute International Research Scholar; and Darren J Gray is a Griffith University Postdoctoral Fellow.

\section{Author details}

${ }^{1}$ National Institute of Parasitic Disease, Chinese Centre for Disease Control and Prevention, Shanghai, PR China. ${ }^{2}$ Department of Epidemiology, School of Public Health, Fudan University, Shanghai, PR China. ${ }^{3}$ Griffith Health Institute, Griffith University, Australia. ${ }^{4}$ MolecularParasitology Laboratory, Infectious Diseases Division, Queensland Institute of Medical Research, Herston, Brisbane, Queensland, Australia. ${ }^{5}$ School of Population Health, University of Queensland, Australia. ${ }^{6}$ Institute for Parasitic Diseases, Sichuan Centre for Disease Control and Prevention, Chengdu, PR China. ${ }^{\text {HHunan }}$ Institute of Parasitic Diseases, World Health Organization Collaborating Centre for Research and Control on Schistosomiasis in Lake Region, Yueyang, Hunan, People's Republic of China.

\section{Authors' contributions}

DPM, YSL, GMW, ZF and JGG conceived the study; RZ, YZ, DCQ, HQZ, WW YSL, GL, ZF, DPM, GMW, JGG and DJG carried out research planning, stool examinations and questionnaire work; DJG, GMW, APT, RZ, RSL and DPM analysed the data; and ZR, DJG, APT and DPM wrote the manuscript with input from all other authors. 


\section{Competing interests}

The authors declare that they have no competing interests.

Received: 10 November 2010 Accepted: 24 March 2011

Published: 24 March 2011

\section{References}

1. McManus DP, Gray DJ, Li YS, Feng Z, Williams GM, Stewart D, Rey-Ladino J, Ross AG: Schistosomiasis in the Peoples' Republic of China: The era of the Three Gorges Dam. Clin Microbial Rev 2010, 23:442-466.

2. Davis GM, Wilke T, Zhang Y, Xu XJ, Qiu CP, Spolsky C, Qiu DC, Li YS, Xia MY, Feng Z: Snail-Schistosoma, Paragonimus interactions in China: population ecology, genetic diversity, coevolution and emerging diseases. Malacologia 1999, 41:355-377.

3. Seto EYW, Wu WP, Liu HY, Chen HG, Hubbard A, Davis GM: Impact of changing water levels and weather on Oncomelania hupensis hupensis populations, the snail host of Schistosoma japonicum, downstream of the Three Gorges Dam. EcoHealth 2008, 5:149-158.

4. Zhu HM, Xiang S, Yang K, Wu XH, Zhou XN: Three Gorges Dam and its impact on the potential transmission of schistosomiasis in regions along the Yangtze River. Ecohealth 2008, 5:137-148.

5. Sleigh A, Jackson S: Dams, development, and health: a missed opportunity. Lancet 2001, 357:570-571.

6. Katz N, Chaves A, Pellegrino J: A simple device for quantitative stool thick-smear technique for schistosomiasis mansoni. Rev Inst Med Trop Sao Paulo 1972, 14:397-400.

7. Guo JG, Ross AG, Lin DD, Williams GM, Chen HG, Li Y, Davis GM, Feng Z, McManus DP, Sleigh AC: A baseline study on the importance of bovines for human Schistosoma japonicum infection around Poyang Lake, China. Am J Trop Med Hyg 2001, 65:272-278.

8. Ross AG, Yuesheng L, Sleigh AC, Williams GM, Hartel GF, Forsyth SJ, Yi L, McManus DP: Measuring exposure to Schistosoma japonicum in China. I. Activity diaries to assess water contact and comparison to other measures. Acta Trop 1998, 71:213-228.

9. WHO: WHO Preventive Chemotherapy in Human Helminthiasis. World Health Organization, Geneva; 2006.

10. Kenworthy JD, Ye P, Wu GC, Yu H, Shi YJ, Li H, Coles GC: Field evaluation of a test for praziquantel resistance in Schistosoma sp. Vet Parasitol 2003, 113:83-87.

11. Liang YS, Dai JR, Ning A, Yu DB, Xu XJ, Zhu YC, Coles GC: Susceptibility of Schistosoma japonicum to praziquantel in China. Trop Med Int Health 2001, 6:707-714

12. Li YS, Sleigh AC, Ross AGP, Li Y, Williams GM, Forsyth SJ, Tanner M, McManus DP: A two-year epidemiological survey in China provides epidemiological evidence for human resistance to re-infection by Schistosoma japonicum. Ann Trop Med Parasitol 1999, 93:629-642

13. Gray DJ, Forsyth SJ, Li RS, McManus DP, Williams GM: An innovative database for epidemiological studies of the neglected tropical diseases. PLoS Negl Trop Dis 2009, 3:e413.

14. Davis GM, Wu WP, Williams G, Liu H-Y, Lu SB, Chen HG, Zheng F, McManus DP, Guo JG: Schistosomiasis japonica intervention study on Poyang Lake, China: the snail's tale. Malacologia 2006, 49:79-105.

15. Spear RC, Seto E, Liang S, Birkner M, Hubbard A, Qiu D, Yang C, Zhong B, Xu F, Gu X, Davis GM: Factors influencing the transmission of Schistosoma japonicum in the mountains of Sichuan Province of China. Am J Trop Med Hyg 2004, 70:48-56.

16. Hubbard A, Liang S, Maszle D, Qiu D, Gu X, Spear RC: Estimating the distribution of worm burden and egg excretion of Schistosoma japonicum by risk group in Sichuan Province, China. Parasitology 2002. 125:221-31.

17. Gray DJ, Williams GM, Li YS, Chen HG, Forsyth SJ, Li RS, Barnett AG, Guo JG, Ross AG, Feng Z, McManus DP: A cluster-randomised intervention trial against S. japonicum in the Peoples' Republic of China: bovine and human transmission. PLOS ONE 2009, 4:e5900.

18. Guo JG, Li YS, Gray D, Ning A, Hu G, Chen HG, Davis GM, Sleigh AC, Feng Z, McManus DP, Williams GM: A drug-based intervention study on the importance of buffaloes for human Schistosoma japonicum infection around Poyang Lake, Peoples' Republic of China. Am J Trop Med Hyg 2006, 74:335-341.

19. Liang S, Seto EY, Remais JV, Zhong B, Yang C, Hubbard A, Davis GM, Gu X, Qiu D, Spear RC: Environmental effects on parasitic disease transmission exemplified by schistosomiasis in western China. Proc Natl Acad Sci U SA 2007, 104:7110-5.

20. Remais J, Liang S, Spear RC: Coupling hydrologic and infectious disease models to explain regional differences in schistosomiasis transmission in southwestern China. Environ Sci Technol 2008, 42:2643-9.

21. Maszle DR, Whitehead PG, Johnson RC, Spear RC: Hydrological studies of schistosomiasis transport in Sichuan Province, China. Sci Total Environ 1998, 216:193-203.

22. Gryseels B, Polman K, Clerinx J, Kestens L: Human schistosomiasis. Lancet 2006, 368:1106-1118

23. Ross AG, Sleigh AC, Li Y, Davis GM, Williams GM, Jiang Z, Feng Z, McManus DP: Schistosomiasis in the People's Republic of China: prospects and challenges for the 21st Century. Clin Micro Rev 2001, 14:270-295.

24. Zou FC, Dong GD, Yang JF, Xie YJ, Zhang YG, Duan G, Zhu XQ: Prevalences of Schistosoma japonicum infection in reservoir hosts in south-western China. Ann Trop Med Parasitol 2010, 104:181-5.

25. Liang S, Yang C, Zhong B, Qiu D: Re-emerging schistosomiasis in hilly and mountainous areas of Sichuan, China. Bull World Health Organ 2006, 84:139-44.

26. Gray DJ, McManus DP, Li YS, Williams GM, Bergquist R, Ross AG: Schistosomiasis elimination: lessons from the past guide the future. Lancet Infect Dis 2010, 10:733-736.

27. Williams GM, Sleigh AC, Li Y, Feng Z, Davis GM, Chen H, Ross AG, Bergquist R, McManus DP: Mathematical modelling of schistosomiasis japonica: comparison of control strategies in the Peoples' Republic of China. Acta Trop 2002, 82:253-262.

28. Wang $L D$, Chen HG, Guo JG, Zeng XJ, Hong XL, Xiong JJ, Wu XH, Wang LY, Wang G, Xia G, Hao Y, China DP, Zhou XN: A strategy to control transmission of Schistosoma japonicum in China. N Eng J Med 2009, 360:121-128

29. Wang LD, Guo JG, Wu XH, Chen HG, Wang TP, Zhu SP, Zhang ZH, Steinmann $P$, Yang GJ, Wang SP, Wu ZD, Wang LY, Hao Y, Bergquist R, Utzinger J, Zhou XN: China's new strategy to block Schistosoma japonicum transmission: experiences and impact beyond schistosomiasis. Trop Med Int Health 2009, 14:1475-1483.

30. Da'Dara AA, Li YS, Xiong T, Zhou J, Williams GM, McManus, Feng Z, Yu XL, Gray DJ, Harn DA: DNA-based vaccine protects against zoonotic schistosomiasis in water buffalo. Vaccine 2008, 26:3617-25.

doi:10.1186/1756-3305-4-43

Cite this article as: Zhu et al: A 5-year longitudinal study of schistosomiasis transmission in Shian village, the Anning River Valley, Sichuan Province, the Peoples' Republic of China. Parasites \& Vectors 2011 4:43.

\section{Submit your next manuscript to BioMed Central and take full advantage of:}

- Convenient online submission

- Thorough peer review

- No space constraints or color figure charges

- Immediate publication on acceptance

- Inclusion in PubMed, CAS, Scopus and Google Scholar

- Research which is freely available for redistribution

Submit your manuscript at www biomedcentral com/submit
C Biomed Central 